\title{
PET and the multitracer concept in the study of neurodegenerative diseases
}

\author{
Henry Engler ${ }^{1}$, Andres Damian², Cecilia Bentancourt ${ }^{2}$
}

\begin{abstract}
The complexity of the pathological reactions of the brain to an aggression caused by an internal or external noxa represents a challenge for molecular imaging. Positron emission tomography (PET) can indicate in vivo, anatomopathological changes involved in the development of different clinical symptoms in patients with neurodegenerative disorders. PET and the multitracer concept can provide information from different systems in the brain tissue building an image of the whole disease. We present here the combination of ${ }^{18} \mathrm{~F}$-flourodeoxyglucose (FDG)

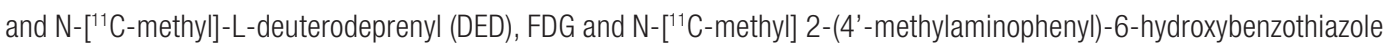
(PIB), PIB and L-[ $\left[{ }^{11} \mathrm{C}\right]-3^{\prime} 4-$ Dihydrophenylalanine (DOPA) and finally PIB and $\left[{ }^{150}\right] \mathrm{H} 2 \mathrm{O}$.
\end{abstract}

Key words: PET, neurodegeneration, F-flourodeoxyglucose, PIB, Alzheimer's disease, Creutzfeldt-Jakob disease.

\section{PET E O CONCEITO DE MULTITRAÇADOR NO ESTUdO DE DOENÇAS DEGENERATIVAS}

RESUMO. A complexidade das reações patológicas do cérebro à agressões causadas por noxa interna ou externa representa um desafio para a imagem molecular. Tomografia por emissão de positron (PET) pode indicar, in vivo, alterações anatomopatológicas envolvidas no desenvolvimento de diferentes sintomas clínicos em pacientes com desordens neurodegenerativas. PET e o conceito de multitraçador pode fornecer informações de diferentes sistemas no tecido cerebral, construindo assim uma imagem da doença como um todo. Nós apresentamos neste artigo a combinação de

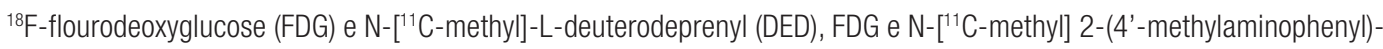
6-hydroxybenzothiazole (PIB), PIB e L-[ $\left.{ }^{11} \mathrm{C}\right]-3$ '4-Dihydrophenylalanine (DOPA) e finalmente, PIB e $\left[{ }^{15} 0\right] \mathrm{H} 2 \mathrm{O}$ Palavras-chave: PET, neurodegenerativas, F-flourodeoxyglucose, PIB, Doença de Alzheimer, Doença de Creutzfeldt-Jakob.

\section{INTRODUCTION}

$\mathrm{T}$ he study of neurodegenerative diseases has experienced a qualitative leap since the introduction of molecular imaging of pathological processes in vivo. PET tracers have the potential to reveal changes in the different stages of many diseases in the brain. They improve the diagnoses increasing our understanding of the pathological processes in the central nervous system.

Different tracer combinations can be the way to characterize brain diseases with a higher level of accuracy. The multitracer concept can help us to achieve a more accurate classification of brain diseases and open the way for better therapeutic strategies.

In this paper we highlight the use of the multitracer concept for the characterization of neurodegenerative diseases and its implications in patient management. The Table 1 describes the different tracers we are going to cover in this review.

\section{FDG AND DED}

${ }^{18} \mathrm{~F}$-flourodeoxyglucose (FDG) is actively transported into the cell by a group of glucose transport proteins (GLUT) and phosphorylated. FDG is trapped in the cells as FDG6-Phosphate avoiding the glycolysis and giving an indirect measure of the glucose uptake in the tissues.

$\mathrm{N}$-[11C-methyl]-L-deuterodeprenyl (DED) binds irreversibly to the enzyme Mono-Amino-oxydase - $\mathrm{B}$ (MAO-B), which is expressed by reactive astrocytes and can be used as a marker for reactive astrocytosis. ${ }^{1-8}$

This study was conducted at the Uruguayan Centre of Molecular Imaging (CUDIM), Montevideo, Uruguay.

${ }^{1} \mathrm{MD}$. PhD and ${ }^{2} \mathrm{MD}$ - Uruguayan Centre of Molecular Imaging (CUDIM), Montevideo, Uruguay.

Andres Damian. Uruguayan Centre of Molecular Imaging (CUDIM) - Av. Ricaldoni 2010 - Montevideo - Uruguay - E-mail: andres.damian@cudim.org 
Table 1. PET molecular probes and their clinical use.

\begin{tabular}{lll}
\hline Radiotracer & Uptake mechanism & Clinical use \\
\hline${ }^{18}$ F-flourodeoxyglucose (FDG) & $\begin{array}{l}\text { Uptake by glucose transporters and trapped into the } \\
\text { cell after phosphorylation by the enzyme hexoquinase }\end{array}$ & $\begin{array}{l}\text { Alzheimer's disease, frontotemporal } \\
\text { degeneration, Creutzfeldt Jakob disease, } \\
\text { lymbic encephalitis, etc. }\end{array}$ \\
\hline$\left[{ }^{11} \mathrm{C}\right.$-methyl] 2-(4'-methylaminophenyl)- \\
6 -hydroxybenzothiazole (PIB) & Binding to amyloid- $\beta$ peptide & Alzheimer's disease, amylodosis \\
\hline $\mathrm{L}-\left[{ }^{11} \mathrm{C}\right]-3$ '4-Dihydrophenylalanine (DOPA) & $\begin{array}{l}\text { Measure of the DOPA- decarboxylase activity at } \\
\text { the level of presynaptic terminals. Evaluation of } \\
\text { presynaptic integrity }\end{array}$ & $\begin{array}{l}\text { Parkinson's disease, atypical } \\
\text { parkinsonisms, endocrine tumours }\end{array}$ \\
\hline $\mathrm{N}-\left[{ }^{11} \mathrm{C}-\right.$-methyl]-L-deuterodeprenyl (DED) & $\begin{array}{l}\text { Monoaminooxidase-B (MAO-B) inhibitor. Uptake by } \\
\text { reactive astrocytes. }\end{array}$ & $\begin{array}{l}\text { Creutzfeldt Jakob disease, Alzheimer's } \\
\text { disease }\end{array}$ \\
\hline$\left[{ }^{15} \mathrm{O}\right] \mathrm{H}{ }_{2} \mathrm{O}$ & $\begin{array}{l}\text { Gold standard for non invasive measurement of } \\
\text { cerebral blood flow (CBF) }\end{array}$ & $\begin{array}{l}\text { Alzheimer's disease, frontotemporal } \\
\text { degeneration, epilepsy, arterio-venous } \\
\text { malformations }\end{array}$ \\
\hline
\end{tabular}

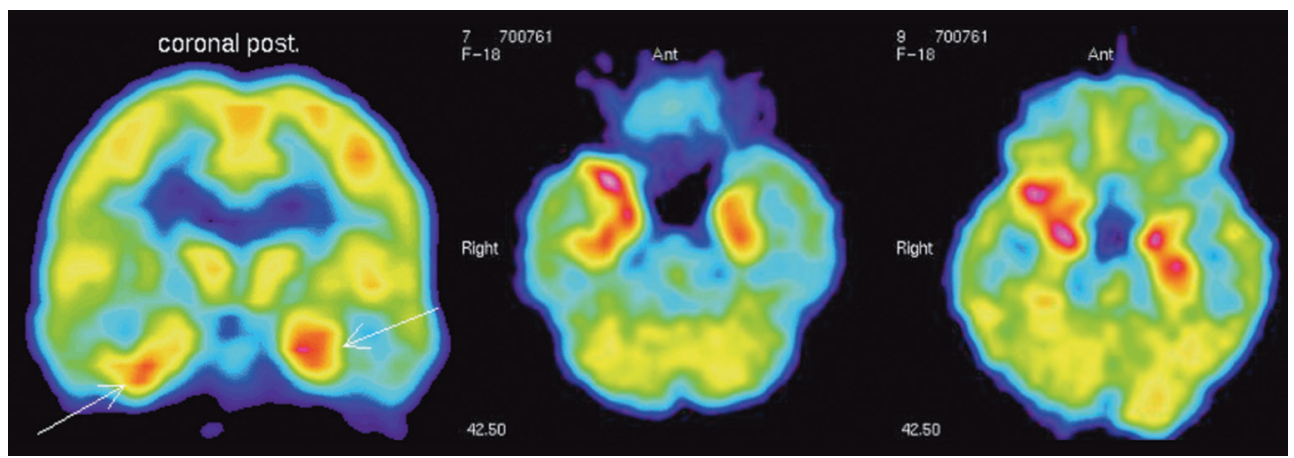

Figure 1. Patient with suspect CJD. The patient, however, had paraneoplasic limbic encephalitis. Left, coronal view: high FDG uptake bilaterally in the medial temporalcortex. Center and right: transaxial view. The FDG pattern is different to that seen in confirmed cases of CJD.

The combination of DED, indicating reactive astrocytosis and FDG, showing changes in the neuronal function, allows us to differentiate between diseases with simultaneous astrocytosis and neuronal death from diseases with astrocytosis and concomitant increased glucose uptake indicating inflammation.

We have used this combination of tracers to differentiate Creutzfeldt-Jakob disease (CJD) from other degenerative processes. CJD is a prion disease clinically characterized by sudden dementia, ataxia and myoclonia. The anatomopathological hallmarks in the brain include: spongiform changes, astrocytosis and neuronal death.

Today there is no cure for CJD, but some other diseases can be treated and therefore it is crucial to achieve an early diagnosis. Inflammation can be produced by an exogenous (bacteria, virus, etc.) or an endogenous agent (autoimmune diseases or paraneoplastic limbic encephalitis) ${ }^{9}$ that is caused by antineuronal antibodies produced in reaction to body neoplasms. In these patients the clinical symptomatollogy can appear as dementia of rapid onset. Sometimes the laboratory tests can help in the diagnosis, but in other cases it is not possible to differentiate between these clinical entities with this information.

The different patterns obtained with PET and appropriated tracer combinations may allow a differential diagnosis modifying the treatment. It is important not only to exclude CJD but also to suggest other diagnoses.

In one patient with dementia of rapid onset and symptoms similar to those found in CJD, high FDG uptake was observed in the limbic system (Figure 1). The medial temporal lobes including the amygdala, the hippocampus and the parahippocampus were the most affected regions. ${ }^{2}$

This pattern of uptake was very different to the pattern described with FDG in patients with confirmed CJD. ${ }^{2}$ Paraneoplastic limbic encephalitis was suspected, a whole body FDG PET was performed and a tumour was found in the left lung. 
An autopsy of the patient revealed an adenocarcinoma of the lung and tumoural antibodies against the brain were demonstrated. The PET examination could quickly distinguish this patient from the other patients with CJD.

In this patient, the quantitative FDG examination proved to be sufficient to make the differentiation between these clinical entities.

Other patient with suspected CJD had a glucose uptake pattern similar to that found in Alzheimer's disease (AD). The metabolism was bilaterally decreased in the temporoparietal regions, but it was conserved in the central parts of the brain and the occipital cortex.

The FDG examination indicating hypometabolism in the parietotemporal areas with conserved metabolism in basal ganglia, cerebellum and sensory motor cortex suggested the possibility that the patient had $\mathrm{AD}$ instead of CJD, but further investigations (biopsy of a salivary gland) revealed

Sjögren's disease. Treatment with corticoids had a dramatic effect in the patient's symptoms.

Parieto-occipital hypometabolism is a conspicuous finding observed mainly in MRI-negative neuropsychiatric systemic lupus erythematosus (SLE). As this cerebral region is located at the boundary of the blood supply territories of all three major arteries, it could be the most vulnerable zone of the cerebrum and may be affected at early stages of the cerebrovascular disease. ${ }^{10}$

An autoimmune disease, producing inflammatory meningo-encephalitis or a perivascular inflammation that affect this region might create a pattern of glucose uptake which is not possible to differentiate with FDG from AD. Patients with Sjörgen's disease can present with symptoms of AD. ${ }^{11}$

It is important to differentiate between these diseases because a dementia with an onset corresponding to CJD or AD may be caused by immunological mechanisms: (System Lupus Erithematosus (SLE), Sjögren disease or a paraneoplasic phenomenon) and therefore can be treated with specific drugs. The result, particularly in the case of Sjögren's disease or SLE, can be dramatic, reversing a dementia condition in hours by administration of corticoids and cyclophosphamide. ${ }^{11}$ Even dementias produced by antineuronal tumour antibodies can be reversed by the extirpation of the tumour. ${ }^{12}$ In a patient with CJD we demonstrate the congruence between pathological findings and PET results, as expressed by the combination DED/FDG. ${ }^{13}$

In the case of rapid onset dementias, a brain investigation with FDG could be followed by a scan of the whole body to quickly discard the possibility of an unknown primary tumour producing antineuronal antibodies. If a brain scan shows hypermetabolism and the body scan is negative, autoimmune diseases or infectious diseases may be suspected. If the brain scan indicates asymmetric hypometabolism, the examination with DED can reveal high ratio DED/FDG suggesting CJD. Hypometabolism similar to that found in $\mathrm{AD}$, but negative to PIB retention, may be caused by a disease affecting the vascular system.

\section{FDG AND PIB}

The combination of FDG and PIB has helped us to understand better the dynamic process in the in vivo amyloid formation. The deterioration in cognition seems related to the decrease in the brain's glucose metabolism, but not directly to the increase in amyloid depositions.

The accumulation of amyloid in the brain appears to be an early process in the development of $\mathrm{AD}$ that increases to a certain level (possibly many years before the debut of the symptoms) and then reaching an equilibrium between aggregation and degradation. ${ }^{14}$

The glucose uptake decreases slightly in the beginning of the disease, reaching a critical point in which it becomes pronounced enough to be detected by PET FDG.

Because the metabolic changes occur later in the development of the disease, FDG can be used to confirm a diagnosis when the symptoms indicate dementia. The tracer however, is not able to discriminate between healthy persons and $\mathrm{AD}$ patients in the early stage of the disease in asymptomatic individuals, whereas PIB offers the possibility to detect amyloid depositions when the symptoms are not evident.

FDG in combination with PIB increases the possibility to perform differential diagnoses. If the PIB examination is negative and FDG reveals a pattern similar to that found in $\mathrm{AD}$, it is possible that a disease with vascular anatomopathological substratum (autoimmune disease?) underlies the symptoms.

Several questions arise from the evidences presented above.

1) Is the presence of amyloid in the brain a process that can be related to aging without consequences for normal functions? It have been suggested a common origin in the pathologic processes that lead to neurofibrillary tangles and amyloid plaques in both aging and $\mathrm{AD}$ [15]. In a study performed in 1999, neurofibrillary tangles were found in the brain of all 39 nondemented persons examined, especially in the hippocampal and parahippocampal areas. The average tangle concentration was found to increase exponentially with age. In contrast, 
plaques were absent in some of the patient brains up to 88 years of age.

Other nondemented patients presented with widely distributed neuritic as well as diffuse plaques throughout the neocortex and limbic structures. It has been proposed that they represent "preclinical" AD. ${ }^{16}$

We suggest that the presence of amyloid is always a sign of degeneration and the depositions will disturb and injure the brain, causing dementia.

Like a city in which the recollection of refuse has been stopped and the garbage is blocking the streets preventing cars from circulating, the amyloid depositions and neurofibrillary tangles block interneuronal communication.

The brain has a highly developed capacity to compensate damage produced by the presence of strange substances accumulating in cytoplasm and interstitium and perturbing functions.

This capacity to compensate is not exclusive of the brain. All the organs in the human body have a reserve that allows normal functions when the tissue is affected by a disease.

We have seen in PET clinical routine extensive tumours invading a whole brain hemisphere before they cause symptoms.

Symptoms of Parkinson's disease (PD) appear when the degeneration of the presynaptic pathway has reached $30-50 \%$ of the striatonigral component. The diagnosis with PET can often be made because the damage is extended enough. We suggest that the brain compensates the slow and progressive biochemical and mechanic damage originated by the increasing presence of amyloid depositions and neurofibrillary tangles until a critical point when the collapse of the function is a fact without the possibility of return.

Although some studies have confirmed that asymptomatic patients may present positive PIB scans, there is a general agreement in the idea that PIB is very sensitive and has a high negative predictive value in the detection of AD. A negative PIB scan would be very important to discard $\mathrm{AD}$ and suggesting other possible diagnoses. ${ }^{17-19}$

If a person having amyloid depositions could live long enough, she or he should develop symptoms of AD. This hypothesis is supported by recent metaanalysis indicating that with longer follow-up periods, the accuracy of PIB to predict AD conversion in Mild Cognitive Impairment (MCI) patients improves significatively. ${ }^{20}$

Education, and aspects of occupational experience have been indicated as factors that may delay the clinical manifestations of $\mathrm{AD} .{ }^{21}$ Other researchers suggest that the effect of education is modest. ${ }^{22}$ The mechanism underlying such a delay could be the presence in educated or trained people of more "activated" neurons from the "reserve pool", which could supply the effects of neuronal death.

2) Not all patients fulfilling international criteria for $A D$ show the presence of amyloid depositions. A discussion concerning new classifications of dementia diseases seems necessary. Frontotemporal dementia (FTD) is a syndrome incuding many entities with different anatomopathological background.

We suggest that the $\mathrm{AD}$ diagnosis must be changed to "Alzheimer's syndrome" or "Cognitive Deficit of Alzheimer's type" (CDAT) because there are many diseases expressing the same symptoms and producing similar changes in glucose uptake.

The diagnosis of $\mathrm{AD}$ must be established in patients with "Alzheimer's syndrome" who have positive PET examinations with PIB or other well-proved amyloid markers. The absence of amyloid depositions is the most questioning result to the diagnosis of $\mathrm{AD}$.

We have examined patients with "Alzheimer's syndrome" without amyloid depositions and it is possible for these patients to have, for example, a disease with a different pathological basis (vasculitis?), which is necessary to investigate.

Since physicians do not treat only symptoms, we need to clarify the underlying pathology to find the proper treatment for patients expressing similar clinical symptoms.

$\mathrm{MCI}$ is considered a transitional stage between normal aging and dementia, especially in early AD. It is known that MCI may have multiple causes, including $\mathrm{AD}$ and other forms of dementia, as well as depression and various psychiatric disorders. Because $\mathrm{MCI}$ is a frequent syndrome, there is a need to establish new methods for predicting the progression to $\mathrm{AD}$.

In a previous study ${ }^{23}$ we demonstrate that PIB retention in $\mathrm{MCI}$ patients is an intermediate step between healthy controls (HCs) and $\mathrm{AD}$ patients. There are $\mathrm{MCI}$ patients who can have either high or low PIB retention. Eleven of twenty-one MCI patients showed high PIB retention in the frontal, parietal and temporal cortices.

The seven MCI patients that at follow-up converted to $\mathrm{AD}$ showed significant high levels of amyloid retention in the brain when compared to $\mathrm{MCI}$ non-converters and $\mathrm{HCs}$. These seven converting MCI patients significantly differed as a group from the non-converts regarding a higher proportion of ApoE-4 carriers, impairment in episodic memory, lower cerebral spinal fluid (CSF) A-beta 1-42 and higher PIB retention. In general, we did not 
detect in this study decreased glucose metabolism in cortical brain areas as earlier reported in $\mathrm{MCI}$ patients. ${ }^{24,25}$ Nevertheless, in some individual MCI patients, decreased regional cerebral metabolic rate of glucose consumption (rCMRglc) was found in such areas as the parietal and temporal cortices. The non-converters in the MCI group had significant higher glucose uptake than $\mathrm{AD}$ patients whereas for the converters the difference was less.

In clinical routine we have observed increased glucose uptake in some of the patients with the diagnosis MCI. ${ }^{26,27}$ The first reaction of neurons against an unspecific injury is a hypermetabolic response. Injured neurons increase the glucose uptake by an enhanced glycogenesis, possibly as a form to economize energy necessary to repair the damages.

Hypermetabolism in patients with MCI may indicate some inflammatory process affecting the brain. These patients, however, might have a negative PIB scan.

Diseases such as autoimmune reactions may produce a perivascular disease or a vasculitis, which, in the acute period, may course with slight hypermetabolism, but in the chronic period, produce hypometabolism. Given that the most sensitive part of the brain is the boundary of blood supply between cerebral arteries, the temporoparietal and the frontotemporal regions will be affected. In a more advanced stadium the patient may have symptoms of $A D$ and the FDG may indicate a pattern similar to the one found in this disease.

The MCI patients classified as converters had amyloid depositions, but the FDG uptake was similar to the controls. The possibilities are that they had increased glucose uptake in the beginning of the amyloid depositions that normalized later; however, it is possible that amyloid depositions do not increase the glucose uptake because they occur slowly under years of progress as a silent, devastating chronic deterioration.

More studies are needed to either confirm or question these interpretations. Based on our findings we suggest that diseases with cognitive impairment causing hypermetabolism in the brain and without amyloid depositions are of a more acute nature. These diseases affect the corridors between arteria cerebri anterior media and posterior and are possibly caused by an autoimmune or inflammatory base. The symptoms may be reverted spontaneously or by treatment.

$\mathrm{AD}$ probably courses with normal metabolism until the damage, induced by the accumulation of plaques and tangles, reaches the critical point in which the neurons can no longer compensate the dysfunction and the symptoms appear (Figure 2).

There is possibly a critical point in which the capacity

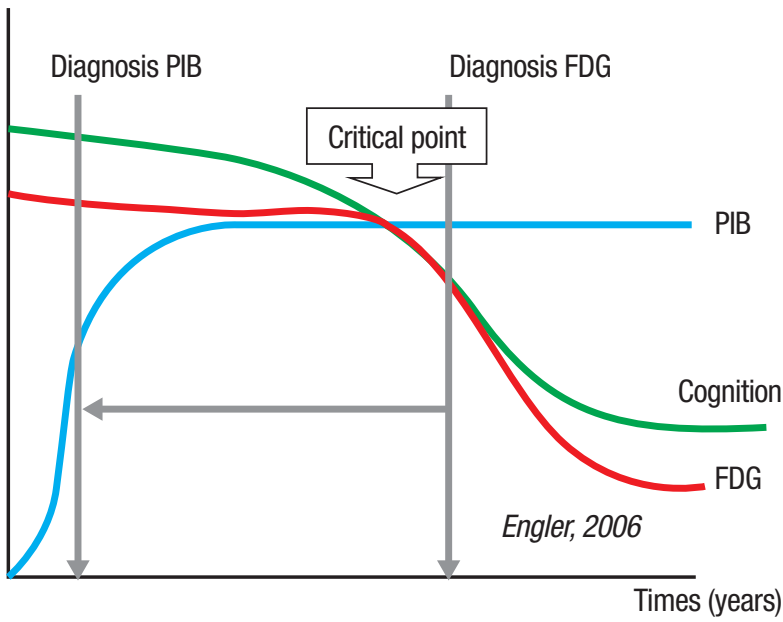

Figure 2. The amyloid deposition seems to begin early in the course of the disease, eventually reaching a "plateau". Glucose uptake is not affected during this period.

of the brain to compensate damage is overcome, with the consequence that symptoms appear. Cognitive impairment follows the decrease in glucose uptake but not the increase of amyloid deposition. FDG is a useful tracer to confirm the diagnosis of $\mathrm{AD}$, but often when damage of brain tissue is pronounced. PIB may detect the presence of the protein before the neurodegenerative changes cause symptoms because the amyloid deposition occurs early in the course of the disease.

\section{PIB AND DOPA}

Amyloid-containing deposits are a neuropathological feature in a wide range of dementias and movement disorders.

In a previous study ${ }^{28}$ we concluded that the normal PIB results in PD do not exclude the possibility that PIB binds to Lewy bodies, Lewy neurites or Amyloid-beta in PD.

Maetzler et al. examined ten patients with Parkinson's disease with dementia (PDD). ${ }^{29}$ Only two PDD patients displayed increased PIB binding to cortical amyloid comparable to $\mathrm{AD}$ patients. The remaining eight patients showed control-like cortical findings, but elevated PIB binding in the pons and mesencephalon. It has been suggested that, in addition to nonspecific binding, PIB uptake in the brainstem may also reflect PDD-related amyloid. ${ }^{29}$

Another study demonstrated the presence of a high affinity binding site for benzothiazole derivatives, including [3H]-PIB, on alpha-synuclein (AS) filaments generated in vitro. ${ }^{30}$

However, no discernible interaction of [3H]-PIB 
was detected with amygdala sections from PD cases containing frequent AS-immunoreactive Lewy bodies. These findings suggest that the density and/or accessibility of AS binding sites in vivo is significantly less than those associated with amyloid-beta peptide lesions. Lewy bodies pathology is therefore unlikely to contribute significantly to the retention of PIB in PET imaging studies. ${ }^{30}$

\section{PIB AND [150]H2O CBF}

In previous studies we have used FDG images based on a 40-60-minute summation as a template to realign PIB images because they give a good anatomic subtract

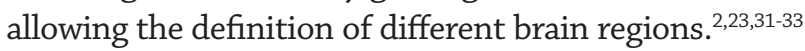
An automatic procedure has been applied to transfer the set of regions of interest (ROI) from FDG images to PIB images. ${ }^{34}$

In the case of PIB, it is difficult to define the brain cortex in HCs in a late PIB summation (40-60 min) because the tracer is retained only in the white matter disturbing the automatic realignment of images.

In the first study performed in Uppsala, ${ }^{33}$ we found that an early summation of the PIB activity frames (6 min) gave images that could be compared with later images of the FDG summation.

The early PIB summation images were realigned to the late FDG images and the rest of the PIB activity frames (7-60 min) were "co-resliced" using the realigned early summation as template.

In this way the ROIs drawn in the late FDG activity image could be transferred automatically to the later (4060 min) PIB summation.

The similarity of the FDG images with the images of the early PIB summation suggested a positive relationship between the cumulative uptake of PIB in a short time interval following bolus administration and the cerebral blood flow (CBF) measured $\left[{ }^{15} \mathrm{O}\right] \mathrm{H} 2 \mathrm{O}$.

A kinetic model with one reversible and one irreversible tissue compartment and three rate constants was used to investigate the PIB net accumulation (Kacc) and unidirectional influx (K1) across the blood brain barrier (BBB) in $\mathrm{HC}$ and $\mathrm{AD}$-patients. ${ }^{35}$

This is in contrast to previous studies in which measures of PIB retention were obtained from reversible kinetic models. ${ }^{36,37}$ The blood input function was determined with arterial sampling in $4 \mathrm{HC}$-subjects and $4 \mathrm{AD}$ patients. Parametric maps of Kacc $=\mathrm{K} 1 \mathrm{k} 3 /(\mathrm{k} 2+\mathrm{k} 3)$ and $\mathrm{K} 1$ were created using a linear algorithm.

Results were compared using the ratio between target uptake and a reference region in a late interval, in HC and $\mathrm{AD}$ patients from studies. ${ }^{31,33}$ The parameter Kacc

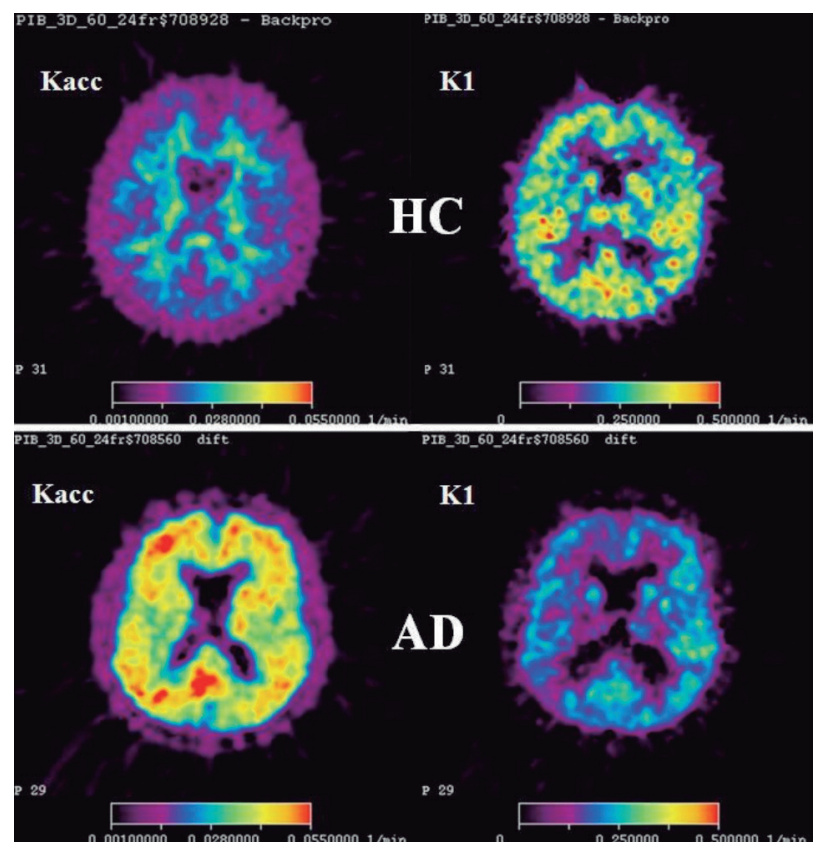

Figure 3. Parametric maps of the net accumulation rate constant Kacc (left) and the unidirectional influx rate constant K1 (right). Upper row: HC subject, lower row: AD-patient.

and the late uptake ratio were found to have similar regional distributions.

The rate constant $\mathrm{K} 1$ for PIB was found to be comparatively larger, demonstrating high extraction of PIB into the brain tissue and indicating that this parameter might reflect $C B F$.

The possibility to replace $\mathrm{K} 1$ by a simple index of the PIB uptake in an early time interval following tracer administration was explored, but needs further validation.

The regional $\mathrm{K} 1$ values were lower in $\mathrm{AD}$ patients than in HCs (Figure 3). Most AD patients had higher Kacc values than $\mathrm{HCs}$ in cortical areas, but some patients had values similar to HCs. However, these patients had lower $\mathrm{K} 1$ than $\mathrm{HCs}$ and did not differ from the other patients regarding this feature.

Furthermore, the effect on $\mathrm{K} 1$ and Kacc of CBF changes were investigated in an animal study using an anesthetized monkey and the following study design: PET scans were performed at baseline and $2 \mathrm{~h}$ later after increasing $\mathrm{PaCO} 2$ with the aid of respiratory control. At both experimental conditions 2 tracers $\left[{ }^{15} \mathrm{O}\right] \mathrm{H} 2 \mathrm{O}$ and PIB was performed within a short time interval. The unidirectional influx rate constant $\mathrm{K} 1$ of PIB was found to be a good index of CBF. The results indicate that the combined information of unidirectional influx and net accumulation of PIB might differentiate between groups of patients with an $\mathrm{AD}$ diagnosis. ${ }^{35}$ 
Many groups have supported this hypothesis, showing that PIB can be used as a functional and pathological tracer in $\mathrm{AD} .{ }^{38-40}$ Recently Chen et al. compared the early dynamic PIB scans with $\left[{ }^{15} \mathrm{O}\right] \mathrm{H} 2 \mathrm{O}$ CBF studies, showing a high correlation with $\mathrm{CBF}$ in patients with $\mathrm{AD}{ }^{41}$ These findings confirm that PIB can also be used as a functional tracer in $\mathrm{AD}$ to explore areas of impaired $\mathrm{CBF}$.

Author contributions. All authors contributed equally in manuscript preparation.

\section{REFERENCES}

1. Ekblom J, Jossan SS, Bergström M, Oreland L, Walum E, and Aquilonius SM. Monoamine oxidase-B in astrocytes. Glia 1993;8:122-132.

2. Engler $\mathrm{H}$, Lundberg PO, Ekbom $\mathrm{K}$, et al. Multitracer study with positron emission tomography in Creutzfeldt-Jakob disease." Eur J Nucl Med Mol Imaging 2003;30:85-95.

3. Fowler JS, Logan J, Volkow ND, Wang GJ. Translational neuroimaging: positron emission tomography studies of monoamine oxidase. Mol Imaging Biol 2005; 7:377-387.

4. Jossan SS, Gillberg PG, Gottfries CG, Karlsson I, Oreland L. Monoamine oxidase B in brains from patients with Alzheimer's disease: A biochemical and autoradiographical study. Neuroscience 1991;45:1-12.

5. Oreland L, Jossan SS, Hartvig P, Aquilonius SM, Långström B. Turnover of monoamine oxidase $\mathrm{B}$ (MAO-B) in pig brain by positron emission tomography using 11C-L-deprenyl. J Neural Transm 1990; 32(Suppl.):55-59

6. Choo ILH, Carter SF, Schöll ML, Nordberg A. Astrocytosis measured by ${ }^{11} \mathrm{C}$-deprenyl PET correlates with decrease in gray matter density in the parahippocampus of prodromal Alzheimer's patients. Eur J Nucl Med Mol Imaging 2014;41:2120-2126.

7. Carter SF, Scholl M, Almkvist O, et al. Evidence for Astrocytosis in Prodromal Alzheimer Disease Provided by 11C-Deuterium-L-Deprenyl: A Multitracer PET Paradigm Combining 11C-Pittsburgh Compound B and 18F-FDG. J Nucl Med 2012;53:37-46.

8. Carter SF, Nordberg A, Schöll M, et al. Investigating astrocytosis with 11C-deuterium-L-Deprenyl in mild cognitive impairment and mild Alzheimer's disease: A multi tracer PET paradigm combining 11C-PIB and 18F-FDG. Alzheimers Dement 2011;7: S110.

9. Corsellis JA, Goldberg GJ, Norton AR. Limbic encephalitis' and its association with carcinoma," Brain 1968;91:481-496.

10. Otte $\mathrm{A}$, Weiner $\mathrm{SM}$, Peter $\mathrm{HH}$, et al. Brain glucose utilization in systemic lupus erythematosus with neuropsychiatric symptoms: a controlled positron emission tomography study," Eur J Nucl Med 1997;24:787-791.

11. Caselli RJ, Scheithauer BW, O'Duffy JD, Peterson GC, Westmoreland BF, Davenport PA. Chronic inflammatory meningoencephalitis should not be mistaken for Alzheimer's disease. Mayo Clin Proc 1993;68:846-853.

12. Provenzale JM, Barboriak DP, Coleman RE. Limbic encephalitis: comparison of FDG PET and MR imaging findings. AJR Am J Roentgenol 1998;170:1659-1660.

13. Engler H, Nennesmo I, Kumlien E, et al. Imaging astrocytosis with PET in Creutzfeldt-Jakob disease: case report with histopathological findings. Int J Clin Exp Med 2012;5:201-207.

14. Engler $\mathrm{H}$, Forsberg A, Almkvist $\mathrm{O}$, et al."Two-year follow-up of amyloid deposition in patients with Alzheimer's disease," Brain 2006;129: 2856-2866.

15. Arriagada PV, Marzloff K, Hyman BT.Distribution of Alzheimer-type pathologic changes in nondemented elderly individuals matches the pattern in Alzheimer's disease. Neurology 1992;42:1681-1688.

16. Price $\mathrm{JL}$ and Morris JC. Tangles and plaques in nondemented aging and 'preclinical' Alzheimer's disease. Ann Neurol 1999;45:358-368.

17. Rowe CC and Villemagne VL. Brain amyloid imaging. J Nucl Med Technol 2013;41:11-18.

18. Rabinovici $G$, Lehmann $M$, Rosen $H$, et al. Diagnostic Accuracy of Amyloid and FDG PET in Pathologically-Confirmed Dementia (S8.005). Neurology 2014;82:(Suppl.):S8.005.

19. Nordberg A, Carter SF, Rinne J, et al. A European multicentre PET study of fibrillar amyloid in Alzheimer's disease. Eur J Nucl Med Mol Imaging 2013;40:104-114

20. Ma Y, Zhang S, Li J, et al. Predictive accuracy of amyloid imaging for progression from mild cognitive impairment to Alzheimer disease with different lengths of follow-up: a meta-analysis. Medicine (Baltimore) 2014;93:e150

21. Stern Y, Alexander GE, Prohovnik I, et al. Relationship between lifetime occupation and parietal flow: implications for a reserve against Alzheimer's disease pathology. Neurology 1995;45:55-60.

22. Fritsch T, McClendon MJ, Smyth KA, Ogrocki PK. Effects of educational attainment and occupational status on cognitive and functional decline in persons with Alzheimer-type dementia. Int Psychogeriatr 2002; 14:347-363.

23. Forsberg A, Engler $\mathrm{H}$, Almkvist $\mathrm{O}$, et al. PET imaging of amyloid deposition in patients with mild cognitive impairment. Neurobiol. Aging 2008;29:1456-1465

24. Anchisi D, Borroni B, Franceschi M, et al. Heterogeneity of brain glucose metabolism in mild cognitive impairment and clinical progression to Alzheimer disease. Arch Neurol 2005;62:1728-1733.

25. Chételat G, Desgranges B, De la Sayette V, Viader F, Eustache F, Baron JC. Mild cognitive impairment: Can FDG-PET predict who is to rapidly convert to Alzheimer's disease? Neurology 2003;60:1374-1377.

26. Kreutzberg GW, Emmert H. Glucose utilization of motor nuclei during regeneration: A [14C]2-deoxyglucose study. Exp Neurol 1980;70: 712-716.

27. Smith CB, Crane AM, Kadekaro M, Agranoff BW, Sokoloff L. Stimulation of protein synthesis and glucose utilization in the hypoglossal nucleus induced by axotomy. J Neurosci 1984; 4:2489-2496.

28. Johansson A, Savitcheva I, Forsberg A, et al. "[(11)C]-PIB imaging in patients with Parkinson's disease: preliminary results". Parkinsonism Relat Disord 2008;14:345-347.

29. Maetzler W, Reimold M, Liepelt I, C. et al. "[11C]PIB binding in Parkinson's disease dementia.," Neuroimage 2008;39:1027-1033.

30. Ye L, Velasco A, Fraser G, et al. In vitro high affinity alpha-synuclein binding sites for the amyloid imaging agent PIB are not matched by binding to Lewy bodies in postmortem human brain. J Neurochem 2008; 105:1428-1437.

31. Engler H, Forsberg A, Almkvist O, et al. Two-year follow-up of amyloid deposition in patients with Alzheimer's disease. Brain 2006;129: 2856-2866.

32. Engler $\mathrm{H}$, Santillo AF, Wang SX, et al. In vivo amyloid imaging with PET in frontotemporal dementia. Eur J Nucl Med Mol Imaging 2008;35:100-106.

33. Klunk WE, Engler $\mathrm{H}$, Nordberg $\mathrm{A}$, et al. "Imaging brain amyloid in Alzheimer's disease with Pittsburgh Compound-B. Ann Neurol 2004;55: 306-319.

34. Andersson JLR, Thurfjell L. Implementation and Validation of a Fully Automatic System for Intra- and Interindividual Registration of PET Brain Scans. J Comput Assist Tomogr 1997;21:136-144.

35. Blomquist G, Engler H, Nordberg A, et al. Unidirectional Influx and Net Accumulation of PIB. Open Neuroimag J 2008;2:14-125.

36. Lopresti BJ, Klunk WE, Mathis CA, et al. Simplified quantification of Pittsburgh Compound B amyloid imaging PET studies: A comparative analysis. J Nucl Med 2005; 46:1959-1972.

37. Price JC, Klunk WE, Lopresti BJ, et al. Kinetic modeling of amyloid binding in humans using PET imaging and Pittsburgh Compound-B. J Cereb Blood Flow Metab 2005;25:1528-1547.

38. Meyer PT, Hellwig S, Amtage F, et al. Dual-biomarker imaging of regional cerebral amyloid load and neuronal activity in dementia with PET and 11C-labeled Pittsburgh compound B. J Nucl Med 2011;52:393-400.

39. Forsberg A, Engler $\mathrm{H}$, Blomquist G, Långström B, Nordberg A. The use of PIB-PET as a dual pathological and functional biomarker in AD. Biochim Biophys Acta 2012;1822: 380-385.

40. Sojkova J, Goh J, Bilgel M, et al. Voxelwise Relationships Between Distribution Volume Ratio and Cerebral Blood Flow: Implications for Analysis of $\beta$-Amyloid Images. J Nucl Med 2015;56:1042-1047.

41. Chen YJ, Rosario BL, Mowrey W, et al. Relative 11C-PiB Delivery as a Proxy of Relative CBF:Quantitative Evaluation Using Single-Session 15O-Water and 11C-PiB PET. J Nucl Med 2015;56:1199-1205. 